\title{
Promoting Relevance in IS Research: An Informing System for Design Science Research
}

\author{
Bill Kuechler \\ University of Nevada, Reno, \\ Reno, Nevada USA
}

kuechler@unr.edu

\author{
Vijay Vaishnavi \\ Georgia State University, \\ Atlanta, Georgia USA
}

vvaishna@gsu.edu

\begin{abstract}
The relevance gap between academic research and the world of practice is a perennial topic of discussion in all fields, including the information technology disciplines. The common sense view of the issue concludes that academic research frequently fails to address the 'street level' problems that business information technology wrestles with, and so isn't interesting to practice. This is primarily a content issue, one that Informing Science characterizes as the academic fascination with easily decomposable problems which leads to the tendency to over-research models that are obvious or trivial to practice. In Information Systems (IS) we have engaged in discipline-wide discussions of this problem for over fifteen years. Some of us feel we have a solution that scales to other information technology fields: design science research (DSR) - learning through building. In this article we overview the relevance gap in information technology research and then introduce design science research (DSR), first as it is practiced in multiple fields and then as it has been refined by the IS academic community specifically for information technology research. We then use the DSR methodology to design an informing system to address the issues we feel inhibit the growth of design science research in IS (DSRIS). We conclude with an analysis of a recently published DSRIS research effort to demonstrate the benefits that obtain from formalized DSR.
\end{abstract}

Keywords: research methods; design science; relevance; research rigor, informing sciences

\section{Introduction}

The accusation of research irrelevance has been leveled at virtually every academic community at one time or another. Management (Morhman, Gibson, \& Mohrman, 2001) engineering (Scalzi, 1996) and even health care (Belkhodja, Amara, Landry, \& Ouimet 2007) have been repeatedly called to task. The challenge to increase research relevance to practice has also been issued to the three information technology disciplines identified by Glass, Ramesh and Vessey (2004) - Computer Science (CS), Software Engineering (SE) and Information Systems (IS) - and each has re-

Material published as part of this publication, either on-line or in print, is copyrighted by the Informing Science Institute. Permission to make digital or paper copy of part or all of these works for personal or classroom use is granted without fee provided that the copies are not made or distributed for profit or commercial advantage AND that copies 1) bear this notice in full and 2) give the full citation on the first page. It is permissible to abstract these works so long as credit is given. To copy in all other cases or to republish or to post on a server or to redistribute to lists requires specific permission and payment of a fee. Contact Publisher@,InformingScience.org to request redistribution permission. sponded to a different degree. Computer Science is the most mathematically grounded and self-referential of the three (Glass, et al., 2004). While most individual academics in CS wish their research to be relevant, there is little published concern on the topic in CS journals and conferences. Software engineering, likely due to the higher direct visibility of its products in the business community 
(Windows and SAP are just two global examples), expresses the need for relevance to practice much more strongly.

Without doubt however, the information technology field most concerned with research relevance to practice is that of the authors, Information Systems. With its academic departments frequently housed in colleges of business and its subject matter drawn from CS, SE, and management science, IS has always been extremely conscious of itself as a "spanning" discipline, between business and computer technology. Thirty years of defending its place as a relevant profession has made the field introspective and as a result a segment of IS has refined a research technique practiced in many disciplines - design [science] research - that makes the sternest attempt we are aware of to insure the relevance of research to practice. In addition it leverages the artifact buildtest cycle to assess its results in a more rigorous manner than is commonly found in information technology disciplines.

From its inception academic research in Information Systems has taken two different approaches: behavioral (management oriented) research and constructivist (build-evaluate) research. Over the last ten years the constructivist approach, termed design science research by its practice community, has gained in number of adherents and importance. We, along with other IS academics, insert the word 'science' into design research to distinguish it from design research as the phrase is understood by non-constructivist researchers in a variety of fields: the study of how artifacts are designed and the characteristics of designers and their practices. In brief, design science research in IS (DSRIS) uses the construction of an information technology artifact and its evaluation learning through building - as the research method. The DSRIS community is therefore much closer to the CS/SE origins of IS than to its management origins, and for this reason we feel DSR as developed in IS has much to offer to all information technology disciplines.

At this point we can hear CS and SE readers saying, "OK, you build something and test it. So what? We've always done that." True; the difference is that as a result of reflecting on the constructivist method and formalizing it DSRIS produces more than just a validated artifact. Every DSRIS effort should be targeted to produce an artifact that is a (partial) solution to an acknowledged business information technology problem. In addition, it produces a "design theory" that prescribes the requirements for a class of artifacts to address similar problems (Jones \& Gregor, 2007). Recently a number of academic design science researchers have suggested methods for still further leveraging a DSRIS project to produce mid-range theory describing the phenomena by which the artifact operates in addition to the prescriptive design theory (Kuechler \& Vaishnavi, 2008a). Finally, because the design science methodology has been formalized to a greater degree than has previously been the case in information technology disciplines, it can be better taught to new generations of researchers. A textbook using patterns to describe DSR efforts at different points in a standard design science research cycle has been developed (Vaishnavi \& Kuechler, 2008) to augment the extended apprenticeship that previously was the preferred (for many, the only) method for teaching constructivist research in information technology. When IS is viewed as an academic informing system (Cohen, 2009; Gill, 2010a;), one of the most important internal clients of that system are doctoral students (Gill, 2010a). DSRIS not only informs these clients directly, but also prepares them to better inform their (eventual, external) business clients.

\section{Rigor and Relevance: A Recurring Dilemma}

Relevance is a highly contextual term; one of the first questions asked in any discussion of the topic is 'relevant to whom'? Here we are concerned only with relevance of academic information technology research to IS/IT practitioners. Information systems (IS) has the longest history of concern with relevance to practice of any of the information technology disciplines, a concern that exploded in the late 1990's during what came to be known as the "core debates" - published 
dialogues in all the disciplines' major journals on what is - or should be - the central topic(s) of the discipline. A large part of the discussion was framed as the "rigor vs. relevance debate" derived from the still prevalent assumption that rigorous research must be methodologically correct, must therefore address relatively small incremental advances in knowledge, and is therefore incompatible with and precludes messy, broadly scoped relevant-to-practice research. Exacerbating this debate was the almost complete retreat of IS practice from IS academics; as Gill and Bhattacharjee (2007) note (see also Gill, 2010a), practitioner authored papers in MISQ had dropped from 40\% in 1980 to virtually none by the mid 1990's. The notion of "rigor vs. relevance" derives from the observations of philosopher/sociologist Donald Schon who famously challenged investigators in all fields to come down from the "high ground of methodological correctness" to the "swamps" of practical relevance (Schon, 1983).

The IS 'rigor vs. relevance' literature has proposed numerous reasons for the relevance gap. The most obvious is the traditional difference in values for academics and practitioners. Academics are paid primarily to educate at college undergraduate levels and above but are also required to demonstrate ongoing currency and prowess in their fields (the fields in which they educate students) by performing research in those fields. Requiring such demonstrations helps keep curricula current, but the research efforts sometimes deteriorate to little more than specious displays of methodological mastery. The problem continues because many journals continue to publish this type of research and this in turn brings academics promotions and merit raises. Even with well intended concerns for relevance, academic research stress tends more toward knowledge production and long term advancement of the field than short term field problem solving. One of the authors spent over 20 years in practice as a software engineer prior to obtaining his Ph.D. and can personally attest to the cultural distance between practice and academics. As one telling example, because most academics research only part time (after teaching obligations) their research programs frequently span several years. Indeed, cultivating a research stream in which one small set of research questions can take an entire career to investigate is considered ideal by many. Yet while in practice, the author favored an IS policy that strongly questioned any development effort longer than 18 months since rapid shifts in the industry environment were a frequent cause of failure for longer term implementations. The vast difference in timeframes of action between academics and practitioners still surprises many members of both groups.

Despite the IS field's obvious concern with relevant research, it is interesting to note that with the exception of some surveys of business managers as to IT issues they found problematic (e.g. Szanja, 1994), no IS papers take an empirical approach to determining exactly what constitutes relevant research results for practitioners. The Informing Science literature makes a strong case that the most relevant business problems are simply too complex to yield to the academic tendency to decomposition (Gill, 2008, 2010b). The most serious effort we are aware of to define "practitioner relevance" comes from the field of organization science (a branch of management studies). Even the seminal IS papers on relevance in research do no actual studies but rather draw results directly from prior organizational science work (e.g., Astley \& Zammauto, 1992; Beyer \& Trice, 1982). The most widely cited IS paper on research relevance (Benbasat \& Zmud, 1999) cites three dimensions of relevance from the management literature: interest to IS/IT professionals, applicability, an indication of utility, and currency of problems addressed. To these the paper adds a dimension not stressed in management studies: accessibility, the tailoring of the semantics and writing style of publications to practitioners.

However, going back to the original organizational studies reveals that the dimensions are more nuanced than is made explicit in the IS literature. According to a widely cited empirical study utilizing multiple large organizations, "Perceived usefulness [of research] requires far more than simply doing research in interesting [to the practitioner] areas" (Mohrman, et al., 2001). Specifically, in this study, companies who were enthusiastic about a research effort when first proposed 
varied considerably in the degree to which they perceived the final results as useful. Further, some practitioners expected definitive answers to problems from the project. The academics however, did not want to invest the time to develop 'pat' solutions. Practice, it seems, wants tactics and well formed methodologies. The expectation that practitioners will take general research results and will generate from them field-ready solutions, although common, is naïve. Several studies have indicated that business demands more rapid action than most academics are comfortable with, and that the practitioner definition of usefulness is narrow and immediate by academic standards.

Gill $(2008,2010 \mathrm{c})$ suggests extreme caution when approaching business problems that are easily decomposable; in all likelihood practice will have investigated these to its satisfaction long before academics become aware of them. However, IS continues to produce valuable proposals for increasing research relevance. Rosemann and Vessey (2008) suggest that research relevance will be increased through the use of "applicability checks" - focus groups or nominal group surveys of businesspersons to determine topics that practitioners find "important" and "applicable" to their work and, thus, relevant. However, as management researchers have determined and as Rosemann and Vessey note, to be relevant to practice research results must not only address a topic of significance, but must be directly applicable to a problem of immediate or recurring concern. We term this attribute, which adds immediate utility to applicability, actionability. Interesting-topractice topics then, as determined in applicability checks, while necessary to relevance, are not sufficient; results must also be actionable. Actionability of research results is difficult to determine in advance unless the methodology used is specifically designed to produce some sort of artifact, something to be used rather than knowledge to explain or predict. Thus DSRIS with its unwavering focus on producing solutions to business problems yields both potentially relevant topics and likely actionable results.

Yet to truly rebut the suspicion of academic research irrelevance we believe practice must actually use research results to good effect. It turns out that persuading IT practitioners to use new methods or techniques or tools calls for additional effort beyond appropriate choice of topic and the performing of research that creates an actionable result. As Weyuker (2007) states, "They [practitioners] are rightfully wary because they haven't seen sufficient evidence and adoption of an unproven approach is just too much of a risk." Research (yes, more research) from both SE and Management Science indicates that the tool or method or technique resulting from research needs to be validated and the validation needs to be done at the scale that reflects real-world projects. Here again, DSRIS at a minimum has a correct focus. Formal validation of research results is a 'built in' part of the methodology (Hevner, March, Jinsoo, \& Ram, 2004). From an informing science perspective, communicating IS research results as relevant is an example of satisfying the complex information needs of business. Complex (as opposed to simple) information needs are characterized by multiple considerations - social, technical, political - all bearing on the risk inherent in a problem area (Skyrius \& Bujauskas, 2010).

\section{Summary}

Producing relevant-to-practice research results is a complex, difficult and lengthy undertaking. Many published reflections on the problem imply that the choice of a topic of interest to practice will lead to relevance; however, empirical studies that have watched industry response to research initially felt to be promising show otherwise. The key to research relevance seems to be what we term actionability for results - practice's perception that the results are understandable, highly focused and when implemented will solve a real, current problem. Beyond that, practitioners are risk adverse in trying new methods or tools in large projects, and require - in addition to comprehensibility, implementability, and promise - some empirical evidence that research results will work in their specific arena. This explains our enthusiasm for DSRIS. Even without multi-year 
grants to fund the work DSRIS generates academic research projects in which an interesting to industry artifact is developed at least to the advanced prototype stage and then subjected to extensive validation in real-world environments.

\section{Design [science] Research: Learning through Building}

Design [science] research - the technique of learning about phenomena of interest by constructing and evaluating artifacts - is common in multiple disciplines, including the information technology disciplines (IS, SE, and CS), engineering, architecture and even education. In most of these disciplines it is referred to as 'design research' (DR) without the word 'science.' In fact, for many engineers and computer scientists the method doesn't have a special name; it's simply "the way we do research." Virtually all the disciplines that use design research are 'applied' disciplines that train students for 'professions' as opposed to pure sciences such as physics or astronomy. The professionals produce artifacts valued by society and the academics (ideally) produce new and better artifacts or new and better ways of producing artifacts. The distinction between pure and applied science was most famously made by Herbert Simon in his book $\underline{\text { Sciences of the }}$ Artificial(1969/1996). Simon's prescriptions for choice among design options did not quite scale to $3^{\text {rd }}$ millennium levels of artifact complexity but much of Sciences of the Artificial is still valuable and widely cited by design researchers in all fields.

As Simon (1969/1996) pointed out, applied disciplines, those that use DR are also, of course, design disciplines, but it is important to note that 'state of practice design' is not considered design research. The element that defines research, at least for academia, is the production of new knowledge. The battle to demonstrate that while design is not research, a research method incorporating design can be rigorous and valid has had to be fought in many disciplines, most recently in IS. The core of the method is the design-build-test cycle. Engineers might design a novel bridge truss and then simulate its performance under load; educators design new curricula and then test for learning improvements; software engineers might conceive a new error detection process and field test it. Note the words 'new' or 'novel' in each of the preceding descriptions since they make the difference between 'just design' and 'design research'. Unfortunately, these words are ambiguous; they have a broad range of values and are interpreted differently by different groups. This is one of the reasons the refinements made to DR by IS researchers are significant.

\section{IS Refinements to DR}

First of all, design science research in IS (DSRIS) has formalized the DR process (see Figure 1) into a well-defined methodology (Vaishnavi \& Kuechler, 2008). Methodologies have precisely defined phases and activities, and it is the definition of the first two phases in DSRIS that establishs a project as research. In a paper that has become doctrinal within the IS community, the problem addressed by a DSRIS effort (the Awareness of Problem phase) must be an acknowledged business problem (Hevner et al., 2004). In the Suggestion phase all prior attempted solutions and/or knowledge and technology that bear on the problem are reviewed. If properly accomplished, these steps of the methodology assure the output of the research will be novel (and thus research) and that it will be at least potentially relevant to practice (aimed at a business problem). As a constructive rather than analytic research approach, DSRIS is uniquely qualified to investigate the complex, non-decomposable problems that are relevant to business (Gill, 2008).

The essentially creative action of design takes place in both the Suggestion phase (idea conception) and the Development phase (idea refinement) of the methodology. The inclusion of a creative step within a research methodology has made DSR suspect to statistics-based research camps in many fields, including IS. The positivist objection is that design science research is strongly dependent on creative acts and these acts are, by definition, not repeatable. Thus, the research is not replicable, and replicability forms one of the cornerstones of positivist research validity. As a 
partial counterpoint to the criticism several IS researchers have begun to codify the steps making up each phase of the Design Science Research Cycle (Figure1) in terms of behavioral patterns (Vaishnavi \& Kuechler, 2008). These patterns are similar to the design patterns familiar to computer science but, instead of suggesting computational routines for recurring computing problems, these patterns specify action steps for recurring design situations and help to demystify the portions of the DSRIS methodology that are essentially creative.

$\begin{array}{lll}\text { Knowledge } & \text { Process } & \text { Logical } \\ \text { Flows } & \text { Steps } & \text { Formalism }\end{array}$

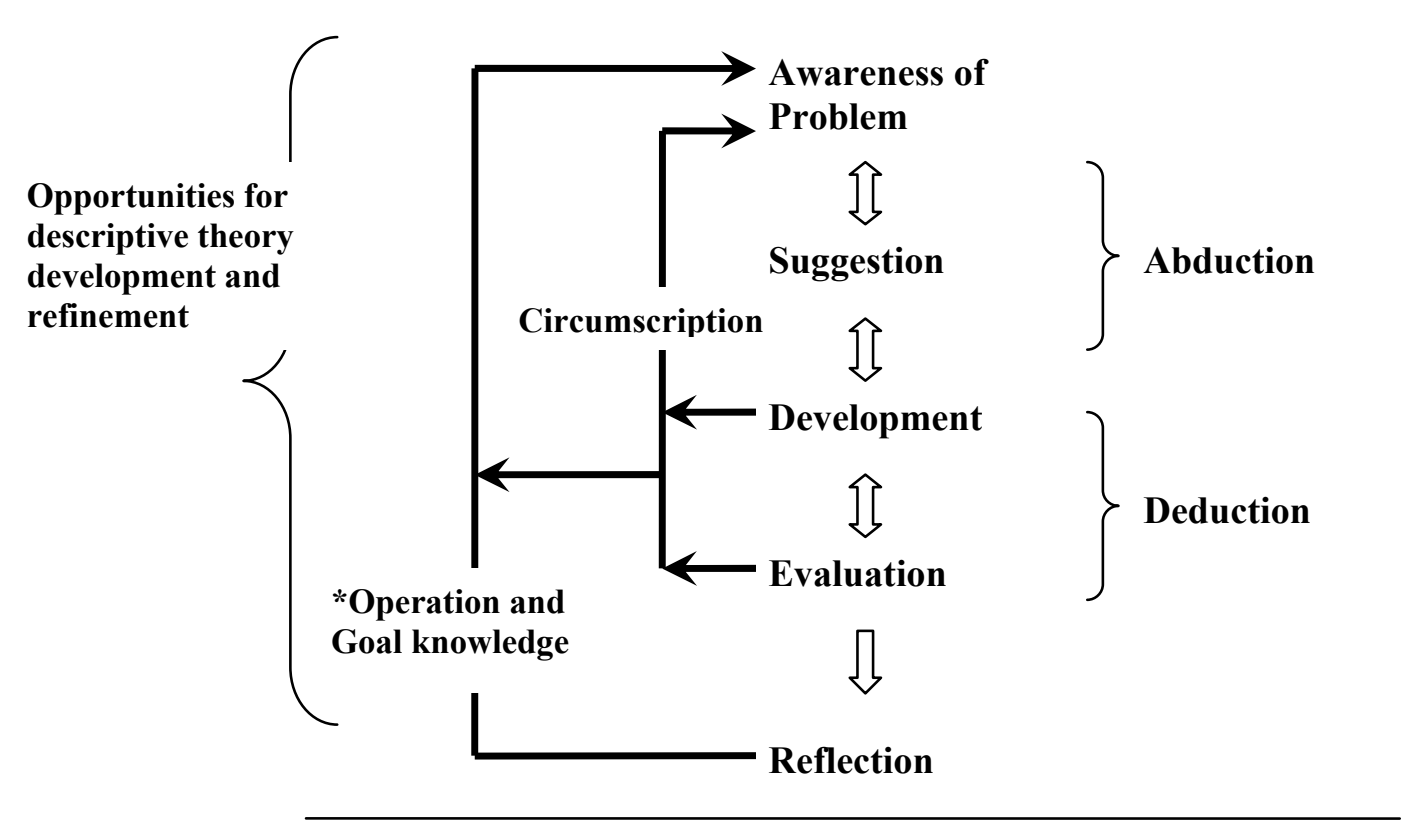

Figure 1: Reasoning in the Design Science Research Cycle

*An operational principle can be defined as "any technique or frame of reference about a class of artifacts or its characteristics that facilitates creation, manipulation and modification of artifactual forms." (Dasgupta, 1996; Purao, 2002).

Evaluation, the next step of the methodology, assures development of the research concept beyond a simple prototype. Except in a completely 'green field' where there is no prior development against which to benchmark the research results, it is no longer adequate to simply develop a working proof of concept. An empirical evaluation in which the research development is compared with the best prior solutions (if available) or a field evaluation under real world conditions is required by the DSRIS community if the research is to be reported as other than preliminary research results. Evaluation techniques called for in the DSR (Hevner, et al., 2004) guidelines include case studies of an artifact in extended business use, field studies in which the artifact is evaluated in multiple real-world projects, controlled experiments, and extensive simulations. The requirement for extensive evaluation of the designed artifact is a relatively new addition to DSRIS and is not explicit in the DR methods of other information technology disciplines. However, it increases the credibility of research to practice (Skyrius \& Bujauskas, 2010), and when the validation takes place in an industry setting, the likelihood of industry use of the research increases as well.

Reflection, the final phase of the DSRIS methodology, is once again specifically focused on increasing relevance to practice; guideline seven (Hevner, et al., 2004) explicitly requires research 
results to be communicated to practice as well as to other researchers. The guideline even specifies the 'translation' of research results into language accessible and interesting to practitioners. It is in this commitment to communicate to its most important external constituency that DSRIS explicitly takes on the role of an institutional informing system (Gill, 2010a).

The decision to declare a DSRIS project complete is another aspect of this type of research that is more ambiguous than for other research methods. Most research procedures are linear - data gathering cannot legitimately be 'revisited', and when data analysis is finished the research has ended. DSRIS however, as indicated by the double headed arrows of Figure 1 is an iterative methodology, with iteration especially likely between Suggestion and Development phases. In this regard it is very similar to iterative system or software development methodologies familiar to all information technology disciplines. Frequently there is no absolute standard against which a DSRIS result can be judged. Instead, consideration of resources, time, and results is blended in a satisficing approach to decide that the artifact as currently constituted and evaluated is "good enough." An integral part of the Reflection phase is therefore the determination of what remains undone in the project and constitutes the subject of future research.

\section{New Knowledge from Design}

As noted, the academic criterion for a design effort to be considered research is the production of new knowledge. New knowledge production is indicated in Figure 1 by the arrows labeled Circumscription and Operation and Goal Knowledge. The Circumscription process is especially important to understanding design science research because it generates understanding that could only be gained from the specific act of construction. Circumscription is a formal logical method (McCarthy, 1980) that assumes that every fragment of knowledge is valid only in certain situations, and validity can frequently not be predicted from theoretical considerations in advance. The knowledge has to be used - in this case as part of a working design - in order to clarify the implications of the theory in a given circumstance. This is not due to a misunderstanding of the theory, but due to the necessarily incomplete nature of any knowledge base. The design process, when interrupted and forced back into an earlier phase in this way, contributes valuable constraint knowledge to the understanding of the always-incomplete-theories that abductively motivated the original design.

As DSRIS has matured the stress has increasingly shifted from the artifact itself to the abstracted requirements and methods for its design as primary deliverable from a DSRIS effort (Jones \& Gregor, 2007). In Figure 1 this is indicated by the arrow labeled "Operational and Goal knowledge." In Information Systems this prescriptive information is termed the design theory (ISDT Information Systems Design Theory) for the class of artifacts of which the specific artifact in the DSRIS project is an instantiation (Walls, Widmeyer, \& El Sawy, 2004). Walls et al. (2004) suggested a specific format for an ISDT, shown in Table 1.

Table 1: Content Categories of a Design Theory (from Walls, et al., 2004)

\begin{tabular}{|l|l|l|}
\hline & & Theory Component \\
\hline \multirow{4}{*}{$\begin{array}{l}\text { Design } \\
\text { Product }\end{array}$} & 1. & Meta-requirements \\
\cline { 2 - 3 } & 2. & Meta-design \\
\cline { 2 - 3 } & 3. & Kernel theories \\
\cline { 2 - 3 } Design Process & 4. & Testable design product hypotheses \\
\hline \multirow{3}{*}{} & 1. & Design method \\
\cline { 2 - 3 } & 2. & Kernel theories \\
\cline { 2 - 3 } & 3. & Testable design process hypotheses \\
\hline
\end{tabular}


An ISDT is broadly divided into description of the functionality of a class of artifacts - the metarequirements and meta-design of the Design Product - and the techniques for creation of an instance of the class - the design method of the Design Process. Both Design Product and Design Process may specify kernel theories, typically defined as "natural science theories from other disciplines" (March \& Smith, 1995) that suggested either the meta requirements or the construction process. However, other authors (Kuechler \& Vaishnavi, 2008b; Venable, 2006) believe that DSRIS can be performed without kernel theories. In fact, they suggest that the ability of DSRIS to generate interesting knowledge even without strong theoretical grounding is a great strength of the method. The kernel theory slots in the template can therefore be considered optional. Testable hypotheses are given in the form of logical statements for both product and process.

\section{Design of a DSRIS Informing System}

The prior sections of the paper have presented the attributes of DSRIS, many of which are significant for overcoming the relevance gap between IS research practice and the practitioner community. However, although some gains have been made by DSR researchers in IS in promoting DSR, it remains a small and frequently misunderstood portion of IS research in total.

Table 2: Core Issues in DSR Acceptance and Informing Activities to Address Them

\begin{tabular}{|c|c|c|c|}
\hline Core Issues & Mediating Factor(s) & $\begin{array}{c}\text { Informing Solution } \\
\text { Activity(s) }\end{array}$ & $\begin{array}{l}\text { Evaluation } \\
\text { Measures }\end{array}$ \\
\hline $\begin{array}{l}\text { Practitioners unaware } \\
\text { of (value of) DSR }\end{array}$ & $\begin{array}{l}\text { Practitioner journals rated } \\
\text { low by academic P\&T com- } \\
\text { mittees } \\
\text { Action and field research } \\
\text { undervalued by IS depart- } \\
\text { ments (which diminishes } \\
\text { contact with the IS practice } \\
\text { community for scholarly } \\
\text { purposes) }\end{array}$ & $\begin{array}{l}\text { Colloquia and seminars promoting the } \\
\text { value of practitioner relevant research - to } \\
\text { students and College of Business (COB) } \\
\text { development efforts. } \\
\text { Colloquia and seminars for influential non- } \\
\text { IS faculty in the COB on the value of DSR, } \\
\text { esp. college curriculum committee mem- } \\
\text { bers } \\
\text { Serve on P\&T committees - department } \\
\text { and college } \\
\text { Serve on colloquium committees }\end{array}$ & $\begin{array}{l}\text { Increased awareness and } \\
\text { acceptance of DSRIS for } \\
\text { promotion and tenure of IS } \\
\text { academics (bylaws and/or } \\
\text { evaluation rubric changes). } \\
\text { Increased number of DSRIS } \\
\text { researchers on departmental } \\
\text { and college P\&T commit- } \\
\text { tees. }\end{array}$ \\
\hline $\begin{array}{l}\text { Non-DSR IS research- } \\
\text { ers unaware of the } \\
\text { value and potential of } \\
\text { DSRIS }\end{array}$ & $\begin{array}{l}\text { Misinterpretation of design } \\
\text { research as 'practice level' } \\
\text { design } \\
\text { Lack of awareness of the } \\
\text { theory generation and theory } \\
\text { testing capability of DSRIS }\end{array}$ & $\begin{array}{l}\text { Colloquia and seminars for non-DSR IS } \\
\text { faculty on the value and outputs of DSR. }\end{array}$ & $\begin{array}{l}\text { Increased awareness and } \\
\text { acceptance of DSRIS for } \\
\text { promotion and tenure of IS } \\
\text { academics (bylaws and/or } \\
\text { evaluation rubric changes). }\end{array}$ \\
\hline $\begin{array}{l}\text { Small number of IS } \\
\text { researchers with de- } \\
\text { sign training }\end{array}$ & $\begin{array}{l}\text { DSR is not stressed in Ph.D. } \\
\text { programs. } \\
\text { IS departments still domi- } \\
\text { nated by behavioral research- } \\
\text { ers. }\end{array}$ & $\begin{array}{l}\text { Encourage and accept visiting appointments } \\
\text { by DSR practitioners } \\
\text { Prepare graduate-level DSRIS textbooks for } \\
\text { Ph.D. seminars in DSRIS } \\
\text { Implement education programs at DSR } \\
\text { conferences and workshops } \\
\text { Design education boot camps for interested } \\
\text { faculty and students. } \\
\text { Promotion of Informatics Schools which } \\
\text { typically pursue more artifact based re- } \\
\text { search than College of Business based IS } \\
\text { departments. }\end{array}$ & $\begin{array}{l}\text { Increased numbers of } \\
\text { DSRIS researchers. } \\
\text { Increased number of aca- } \\
\text { demic IS departments where } \\
\text { DSRIS is accepted. } \\
\text { Increased number of DSRIS } \\
\text { seminars at Ph.D. granting } \\
\text { IS departments. }\end{array}$ \\
\hline $\begin{array}{l}\text { Inability to publish } \\
\text { DSRIS research in top } \\
\text { tier IS journals }\end{array}$ & $\begin{array}{l}\text { Lack of awareness of the } \\
\text { theory generation and theory } \\
\text { testing capability of DSRIS }\end{array}$ & $\begin{array}{l}\text { Serve on editorial boards of top journals. } \\
\text { Promote attendance at DSR seminars to } \\
\text { SE's and AE's of top tier journals }\end{array}$ & $\begin{array}{l}\text { Increased number of jour- } \\
\text { nals accepting DSRIS. } \\
\text { Increasing number of } \\
\text { DSRIS publications overall. }\end{array}$ \\
\hline $\begin{array}{l}\text { Limited grant oppor- } \\
\text { tunities for DSRIS }\end{array}$ & $\begin{array}{l}\text { Lack of awareness of DSR as } \\
\text { a paradigm and its value to } \\
\text { the US and global econo- } \\
\text { mies. }\end{array}$ & $\begin{array}{l}\text { Specific communications with granting } \\
\text { agency officials concerning DSRIS and its } \\
\text { economic and scientific value. } \\
\text { Suggest DSRIS programs at granting agen- } \\
\text { cies and volunteer for positions at granting } \\
\text { agencies. }\end{array}$ & $\begin{array}{l}\text { New programs funding } \\
\text { DSRIS research efforts. } \\
\text { Increased awareness of } \\
\text { DSRIS within funding } \\
\text { agencies measured by inter- } \\
\text { action with DSRIS academ- } \\
\text { ics. }\end{array}$ \\
\hline
\end{tabular}


Many of the reasons for the small penetration and diminished status of DSRIS can be traced to a lack of accurate information on DSRIS in both IS academic and IS practice communities. Appropriately then, in this section of the paper we use the principles of DSR to develop a preliminary design for an DSRIS informing system to addresses the lack of information on DSRIS in both the academic and practice communities.

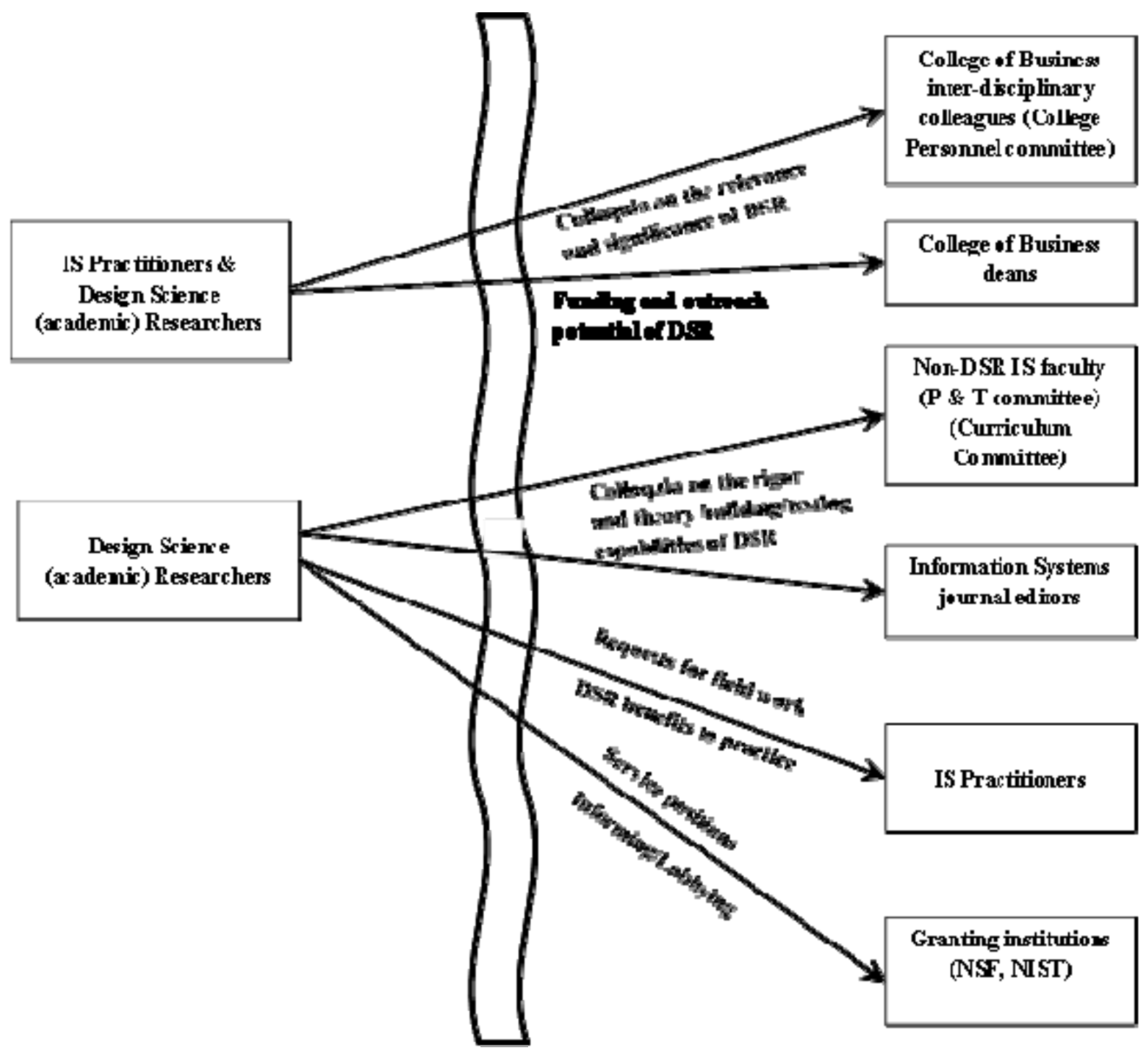

Figure 2: A Design Science Research in Information Systems Informing System Model

Following the design research cycle of Figure 1, the Core Issues column in Table 2 corresponds to the problem determined during the Awareness of Problem phase. The Mediating Factor column of the table contains situations and issues that are addressable by an Academic Informing System (Gill, 2010a). The basic structure of such an informing system has been previously defined (Gill, 2010a) and in DSR terms constitutes a meta-design (see Table 1); a pre-existing meta-design is typically discovered and assessed during the Suggestion phase of the design research cycle (Figure 1). The actual informing system itself will be an instantiation of the meta-design - the basic 
academic informing structure(s) - accomplished by positioning the activities and actors listed in column 3 of Table 2, Informing Solution Activity(s) within the structure specified by the metadesign. These activities were arrived at during the Design portion of the DSR cycle (Figure 1). This process is essentially an extended reflection on the Core Issues of Table 2 and on knowledge gathered through experience with and prior research on the academic and practitioner environments in which the informing system (the designed artifact of the DSR project) will function. The system is represented graphically in Figure 2. Boxes in the figure represent actors; those on the left of the 'barrier' are information sources; those on the right are information receivers. The labeled arrows are information flows, each addressing a Core Issue from Table 2 or an aspect of an issue.

An integral part of any design science research program following the design and implementation of the designed artifact is the Evaluation phase (Hevner, et al, 2004; see Figure 1). The fourth column of Table 2 lists the output measures that indicate the success of the designed artifact, the DSRIS Informing System. It is important to note timing issues in the evaluation of what Gill (2010d) terms a complex informing system. We have already noted the complex web of relationships and feedback loops between information senders and receivers in the system; these give rise to delays and time sequences in the results of informing activities. These are illustrated in the simple process model of one aspect of the informing system shown in Figure 3.

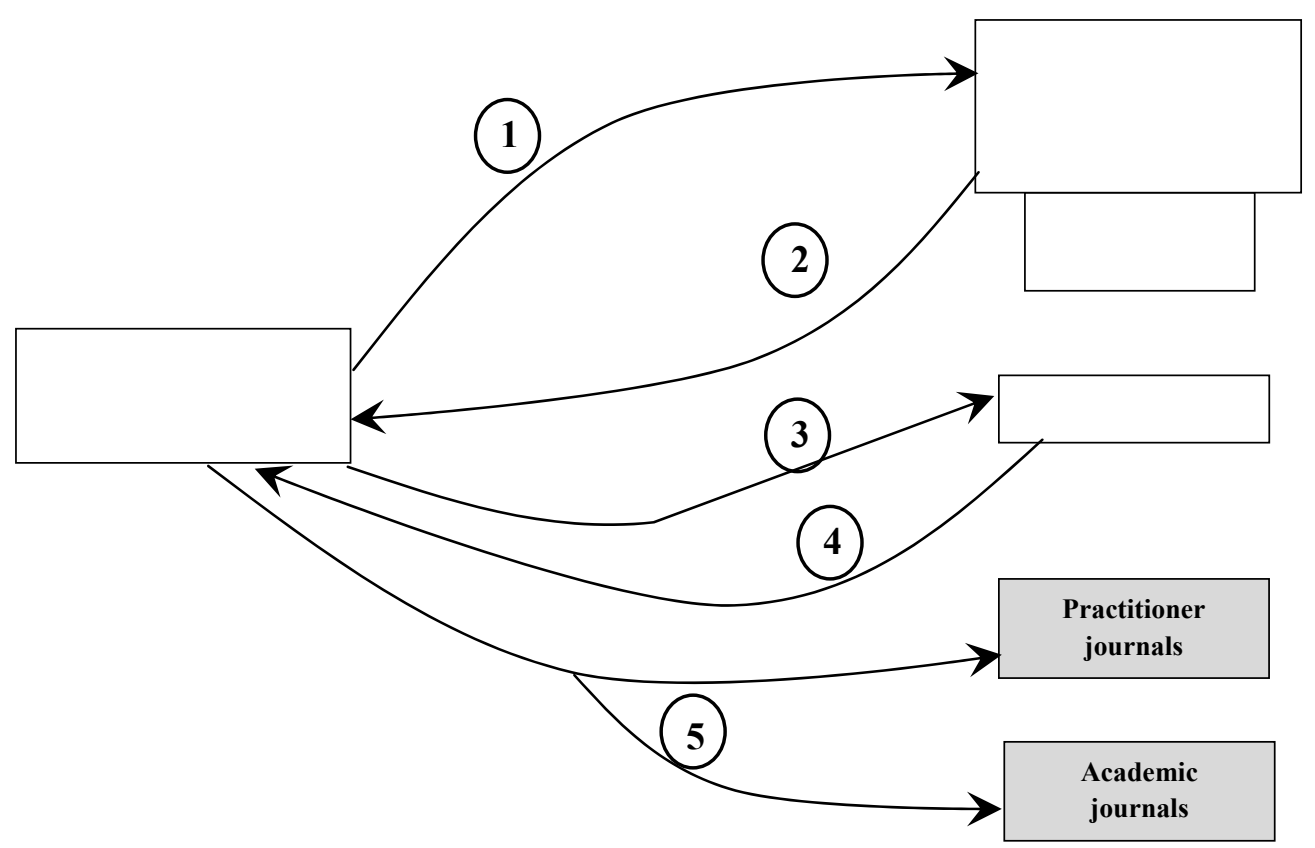

Figure 3: A Process Model of the DSRIS Informing System (Direct evaluation measures of the informing system are in gray boxes)

Each arrow in Figure 3 represents an information flow. Arrow 1 is information concerning the value of DSRIS communicated to College of Business Deans and Personnel Committees. When successfully transmitted, this information leads to flow 2, evidence of increased acceptance of DSRIS in the compensation plans for IS departments. This, in turn, leads to 3, communication of the value of DSRIS to IS practice and solicitations for research opportunities in industry settings. Flow 4 is the result of successful transmission of flow 3 and indicates joint research with the practitioner community; this ultimately leads to joint publications in both academic and practitio- 
ner journals - flow 5 . Note that Figure 3 is only part of the web of the total informing system and that increased DSRIS publications (Flow 5) are both a measure of the success of the informing system and constitute further communications within that system to increase the visibility and status of DSRIS and lead to further success measures.

While no formally defined informing system such as the one described above has been embraced by the DSRIS community, many elements of that system have already been initiated. A conference specifically for design science researchers, DESRIST (design science research in information systems and technologies) began in 2006 and many of the IS field's largest conferences such as ICIS and AMCIS have added a Design Research track. As a result of the efforts of senior DSRIS practitioners such as Dr. Alan Hevner of the University of South Florida, several programs supporting DSRIS have been put in place at the NSF. Additionally and very significantly, a several top tier journals including the European Journal of Information Systems and MIS Quarterly publish far more DSRIS research than previously and MISQ has instituted an Associate Editor position specifically for DSR. An example of the type of relevant yet rigorous research encouraged by the opportunity for top-tier publication of DSRIS is presented in the next section.

\section{DSR Now and Future}

An excellent recent DSRIS effort which successfully demonstrates the 'relevance potential' of design science research is "CONQUER: A Methodology for Context-Aware Query Processing on the World Wide Web" (Storey, Burton-Jones, Sugumaran, \& Purao, 2008). Relative to earlier DSR research, CONQUER explicitly presents:

- the real-world problem the research addresses

- a working prototype

- design and grounding knowledge for the prototype

- an extensive experimental evaluation of the prototype

Search interfaces are an integral part of many business software systems, and making searches more intuitive and search results more accurate is an obvious way of increasing business productivity. This is precisely the issue CONQUER (CONtext aware QUERy processing) addresses. Tightly tying the project to a business problem not only makes the research more relevant to practice, but also gives the research team more scope in which to explore the potential of the concepts. A working prototype with experimental validation gives the work more credibility; it shows that not only does the method work, but it works in a 'near business' context. Finally, producing an explicit design theory for the artifact makes it easier for practitioners as well as other researchers to incorporate the research results into their work or build on the results to advance the field still further. In short, anyone reading the description of CONQUER would immediately know its potential contribution to business information technology and how to incorporate similar results into other systems.

A close examination of CONQUER also reveals a potential problem for DSR that will need to be dealt with as the field unfolds, the problem of 'over-specification'. So aware are CONQUER researchers of recent widely cited guidelines for DSRIS projects that they explicitly map their contribution to those guidelines in a table in the paper. We have seen this within other recent DSRIS publications as well. We suspect it may be due to a growing tendency on the part of journal reviewers to interpret DSRIS guidelines as a requirements checklist and to disqualify research if it does not meet every point of the list. As the authors of the guidelines themselves stress, they were intended to direct and clarify, not to specify. As much as we applaud the increasing definition suggested for DSRIS over the last two decades, the method is simply too powerful and addresses too broad a range of research questions to be constrained by a static checklist. For example, the 
ability of DSR to provide valuable results in previously un-researched areas, areas without prior theoretical background or investigations, is a strength of the method. Yet for such cases it would be difficult or impossible to compare the results to prior examples. Further, the conservative nature of business would make it exceptionally difficult to get permission to test truly new technology in actual industry settings. However, we find working in a still rapidly changing arena exciting; helping design science research evolve in a way that maintains its current stress on realworld relevance while not stifling it with blind adherence to a static checklist, is a challenge for everyone who practices in the field.

\section{Conclusion}

The potential for academic research in information technology to make a rigorous, long-term contribution to the information technology field and to be relevant to practice is difficult to achieve. Information technology practitioners and academics work on different time frames, hold different values concerning the contribution of research, and have different compensation structures that tend to reinforce rather than diminish the differences. We have suggested a possible approach to the problem - design science research as refined over an extended period of time by Information Systems researchers - DSRIS. As we demonstrated in our examination of a current DSR project, relevant DSR as promoted by current DSRIS guidelines is good for everybody-even or maybe especially for the researchers themselves.

\section{References}

Astley, W., \& Zammuto, R. (1992). Organization science, managers, and language games. Organization Science, 3(4), 443-460.

Belkhodja, O., Amara, N., Landry, R., \& Ouimet, M. (2007). The extent and organizational determinants of research utilization in Canadian health services organizations. Science Communication, 28(3), 377417.

Benbasat, I. \& Zmud, R. (1999). Empirical research in information systems: The practice of relevance. MIS Quarterly, 23(1), 3-16.

Beyer, J., \& Trice, H. (1982). The utilization process: A conceptual framework and synthesis of empirical findings. Administrative Science Quarterly, 27(4), 591-622.

Cohen, E. (2009). A philosophy of informing science. Informing Science: the International Journal of an Emerging Transdiscipline, 12, 1-15. Retrieved from http://www.inform.nu/Articles/Vol12/ISJv12p001-015Cohen399.pdf

Dasgupta, S. (1996). Technology and creativity. New York: Oxford University Press.

Glass, R., Ramesh, V., \& Vessey, I. (2004). An analysis of research in computing disciplines. Communications of the ACM, 47(6), 89-94.

Gill, T. G. (2008). Reflections on researching the rugged fitness landscape. Informing Science: The International Journal of an Emerging Transdiscipline, 11, 165-196. Retrieved from http://www.inform.nu/Articles/Vol11/ISJv11p165-196Gill219.pdf

Gill, T. G. (2010a). Informing Business: Research and Education on a Rugged Landscape (Chapter 2: Academic informing systems, 27-46). Santa Rosa, CA: Informing Science Press.

Gill, T. G. (2010b). Informing Business: Research and Education on a Rugged Landscape (Chapter 4: The complexity of business, 87-115). Santa Rosa, CA: Informing Science Pres.

Gill, T. G. (2010c). Informing Business: Research and Education on a Rugged Landscape (Chapter 15: Informing practice, 471-508). Santa Rosa, CA: Informing Science Press.

Gill, T. G. (2010d). Informing Business: Research and Education on a Rugged Landscape (Chapter 12: Complex informing: A synthesis, 359-372). Santa Rosa, CA: Informing Science Press. 
Gill, T. G., \& Bhattacherjee, A. (2007). The informing sciences at a crossroads: The role of the client. Informing Science: the International Journal of an Emerging Transdiscipline, 10, 17-40. Retrieved from http://www.inform.nu/Articles/Vol10/ISJv10p017-039Gill317.pdf

Hevner, A., March, S., Jinsoo, P., \& Ram, S. (2004). Design science in information systems research. MIS Quarterly, 28(1), 75-105.

Jones, D., \& Gregor, S. (2007). The anatomy of a design theory. Journal of the Association for Information Systems (JAIS), 8(5), Article 19.

Kuechler, W., \& Vaishnavi, V. (2008a). The emergence of design research in information systems in North America. Journal of Design Research, 7(1), 1-16.

Kuechler, W., \& Vaishnavi, V. (2008b). On theory development in design science research: Anatomy of a research project. European Journal of Information Systems, 17(5), 1-23.

March, S., \& Smith, G. (1995). Design and natural science research on information technology. Decision Support Systems, 15(4), 251-266.

McCarthy, J. (1980). Circumscription - A form of non-monotonic reasoning. Artificial Intelligence, 13, 2739.

Mohrman, S., Gibson, C., \& Mohrman, A. (2001). Doing research that is useful to practice: A model and empirical exploration. Academy of Management Journal, 44(2), 357-375.

Purao, S. (2002), Design research in the technology of information systems: Truth or dare. In GSU Department of CIS Working Papers, Atlanta, GA.

Rosemann, M., \& Vessey, I. (2008). Toward improving the relevance of information systems research to practice: The role of applicability checks. MIS Quarterly, 32(1), 1-22.

Szajna, B. (1994). How much is information systems research addressing key practitioner concerns? Data Base (May), 49 -59.

Scalzi, J. (1996). Research relevance: Communication is key. Civil Engineering, 66(8), 6-7.

Schon, D. (1983). The reflective practitioner. New York: Basic Books.

Simon, H. (1996, first published 1969). The sciences of the artificial. Cambridge, MA: MIT Press.

Skyrius, R., \& Bujauskas,V. (2010). A study on complex information needs in business activities. Informing Science: the International Journal of an Emerging Transdiscipline, 13, 1-14. Retrieved from http://www.inform.nu/Articles/Vol13/ISJv13p001-013Skyrius550.pdf

Storey, V., Burton-Jones, A., Sugumaran, V., \& Purao, S. (2008). CONQUER: A methodology for contextaware query processing on the World Wide Web. Information Systems Research, 19, 3-15.

Vaishnavi, V., \& Kuechler, W. (2008). Design science research methods and patterns: Innovating information and communication technology. New York: Auerbach.

Venable, J. (2006). The role of theory and theorizing in design science research. Proceedings of DESRIST 2006. Claremont, CA.

Walls, J., Widmeyer, G., \& El Sawy, O. (2004). Assessing information system design theory in perspective: How useful was our 1992 initial rendition? Journal of Information Technology Theory and Application, 6(2), 43-58.

Weyuker, E. (2007). Software engineering research - From cradle to grave. Proceedings of ESEC/FSE'07 (European Software Engineering Conference), Dubrovnik, Croatia, ACM. 


\section{Biographies}

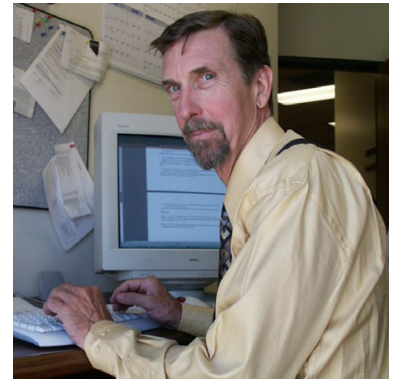

Bill Kuechler is a professor of Information Systems and Chair of the Information Systems discipline at the University of Nevada, Reno. He holds a BS in Electrical Engineering from Drexel University and a Ph.D. in Computer Information Systems from Georgia State University. Bill's academic career follows a successful industry career in information systems development and consulting. Bill's two primary research themes are the cognitive bases of IS use, development and education, and design science research in IS. He has published in MIS Quarterly, Communications of the ACM, IEEE Transactions on Knowledge and Data Engineering, and other international conferences and journals. Dr. Kuechler is a member of AIS, IEEE and ACM.

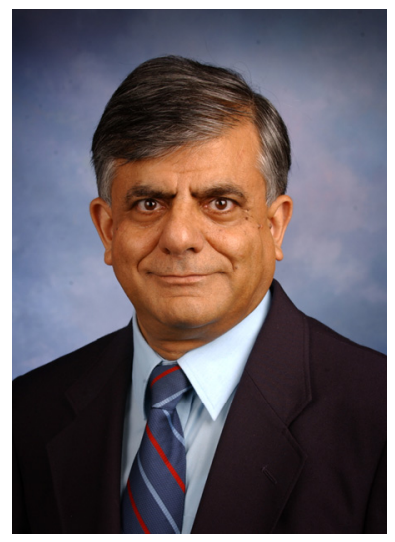

Vijay Vaishnavi is Board of Advisors Professor of Computer Information Systems and Professor of Computer Science at Georgia State University. He has conducted research in efficient data structures and algorithms, software development, information integration and web mining, and design science research methods. His research has been funded by research agencies such as the National Science Foundation as well as by the industry. He has been a consultant to various companies and organizations including IBM, AT\&T, and Bell Northern Research in the area of object-oriented modeling and management. $\mathrm{He}$ has published in IEEE Transactions on Software Engineering, ACM Computing Surveys, MIS Quarterly, and other international conferences and journals. He is currently a Senior Editor of MIS Quarterly and is on the editorial boards of several other scholarly journals. Dr. Vaishnavi is an IEEE Fellow and in 2007, he was awarded Lifetime Achievement Award in Design Sciences. 